\title{
A interlocução entre professor tutor e aluno na educação a distância
}

\section{The tutorage's interlocutory dimension between distance education's tutors and tutees}

\author{
Marta Maria Gonçalves Balbé*
}

\begin{abstract}
RESUMO
Este artigo apresenta um relato de experiência de tutoria no Curso de Pedagogia - Séries Iniciais na modalidade a distância. Na EAD o tutor é responsável por manter uma comunicação ativa com seus alunos. Para isso é necessário que ofeedback do professor-tutor ao aluno seja constante. Para o aluno da EAD é mais frustrante não obter uma resposta do professor do que para o aluno da presencial que tem o professor presente em sala de aula toda semana. Para garantir esta comunicação, o professor-tutor deve manter uma rotina de atendimento aos alunos e canais abertos de comunicação. O tutor deve estar constantemente atento para as necessidades de seus alunos, sejam elas pedagógicas ou afetivas.

Palavras-chave: tutoria, educação a distância, mediação pedagógica, orientação acadêmica.
\end{abstract}

\begin{abstract}
This article presents a case study of a tutorial experience on a Distance Education's undergraduate course in the field of Pedagogy with major in fundamental education at at the Federal University of Paraná. The tutor on a Distance Learning Process is responsible for keeping an active

Mestre em Educação nas Ciências e professora tutora do Centro Associado de Maringá. E-mail: marta.balbe@usb.org.br
\end{abstract}


communication with her students. Therefore it's necessary that the feedbak offered by the tutor to the student be an on going process. On Distance Education, it is far more frustrating for the tutees not getting a response from their professors and tutors than it is for the students who go to presencial courses and therefore have the professor's presence on a weekly basis. In order to garantee an stable communication with students, the tutor must keep a tutorage routine and an opening channel of communication. The tutor should be constantlly alert to students' needs, be it of either an intelectual or afective order.

Key-words: tutoring, distance education, pedagogic mediation, tutorage orientation.

\section{Introdução}

Ao abordar a questão dos novos rumos em educação, DIDONET (1998) comenta que

...a escola, como locus da aprendizagem, como lugar privilegiado para as pessoas - desde a mais tenra idade - adquirirem e construirem conhecimentos, precisa atualizar-se, ser uma organização do seu tempo. Se não o fizer, será anacrônica, perderá sua atratividade e importância, não será mais do que um registro histórico nas cavernas do passado.

Esse "atualizar-se" significa compreender que o mundo passa por mudanças tão rápidas e inesperadas que sequer temos condições para interpretálas adequadamente, sentindo, no entanto, os reflexos de seu caminhar e das suas conseqüências.

Os avanços tecnológicos tornaram o mundo sem fronteiras. As novas relações sociais, em nível micro e planetário, criaram novos conceitos histórico-geográficos, culturais e econômicos. Por isso, impõe-se hoje uma nova concepção de história, de sociedade e, portanto, de homem, o que implica um novo conceito de escola e de seu papel social.

Frente a esses desafios, a educação precisa buscar a compreensão e interpretação do contexto no qual ela se desenvolve para situar o sujeito no 
mundo que o abriga e oferecer meios e condições para que ele participe, mais conscientemente, dos desafios que deverá enfrentar.

Entre os novos rumos da educação encontra-se a Educação a Distância. Para PRETI (1996, p. 19) "é uma modalidade não-tradicional, típica da era industrial e tecnológica, cobrindo distintas formas de ensino-aprendizagem, dispondo de métodos, técnicas e recursos, postos à disposição da sociedade". Esta modalidade de ensino, diferenciada da presencial convencional, vem privilegiar àquelas pessoas que já têm algum nível de escolaridade, mas que por motivos os mais diversos não tiveram oportunidade de concluir os estudos no tempo hábil e, sobretudo, oportunizar o acesso ao saber sistematizado para os que não tiveram acesso a ela na idade adequada.

A nova Lei de Diretrizes e Bases - 9.394/96, no art. 80, cita que o Poder Público incentivará o desenvolvimento e a veiculação de programas de educação a distância, em todos os níveis e modalidades de ensino, e de educação continuada tendo em vista que a EAD tem se destacado no mundo inteiro e também está conquistando um importante espaço no Brasil. Segundo PRETI (1996, p. 19),

...a eficácia da Educação a Distância, está, hoje, inegavelmente comprovada, o que não significa falta de questionamentos e estudos contínuos sobre essa modalidade. Há uma significativa produção internacional que aponta aspectos positivos e negativos referentes ao sistema. O importante é que se conceba a Educação a Distância como um sistema que pode possibilitar atendimento de qualidade, acesso ao ensino, além de se constituir em forma de democratização do saber.

Por isso, as instituições superiores estão se articulando com o objetivo de difundir e qualificar pessoal para atender os programas de EAD. Dentre as diversas instituições superiores dispostas a enfrentar este novo desafio, encontra-se a Universidade Federal do Paraná por meio do Setor de Educação e do Núcleo de Educação a Distância da UFPR - NEAD, oferecendo Cursos de Especialização de Professores e Capacitação de Tutores, e principalmente oportunizando projetos de parceria com entidades civis para ingresso no Curso de Pedagogia - Séries Iniciais do Ensino Fundamental na Modalidade de Educação a Distância. O objetivo deste curso é colaborar com a demanda criada pela LDB para a necessária qualificação, até 2007, dos profissionais da educação que não tiveram o privilégio de ingressar na universidade após a 
conclusão do Ensino Médio. É neste cenário que se contextua o curso de graduação a distância ofertado pela UFPR em parceria com entidades civis, no intuito de oportunizar a política de inclusão iniciada pelo MEC no sentido de ampliar de oportunidades educacionais para os nossos educadores. A partir desta experiência pioneira no Estado do Paraná, esperamos ver consolidadas novas medidas governamentais para o financiamento de cursos desta monta, públicos e a distância, que beneficiarão muitos segmentos da sociedade, já que o que se faz pelo educador interfere diretamente na qualidade da formação do nossos educandos.

\section{Uma experiência nova vivenciada}

A União Sul Brasileira de Educação e Assistência Social é responsável por escolas/colégios adventistas dos Estados do Paraná, Santa Catarina, Mato Grosso do Sul e Rio Grande do Sul. Em 1999, nossa instituição, preocupada com a qualificação do pessoal docente da rede, buscou na UFPR uma parceria para qualificar um grupo de professores que trabalham com as séries iniciais.

Para efetivação da parceria e consolidação do projeto se fez necessária a formação de tutores, levando um grupo de nossos profissionais a participarem do Curso de Especialização de Professores e Aperfeiçoamento para Capacitação de Tutores ofertado pelo NEAD da UFPR. Esta iniciativa respondeu a necessidade de formação de um contingente de profissionais em nossa instituição que participariam no processo de implantação do curso de graduação a distância.

Como coordenadora pedagógica de 14 unidades escolares adventistas da região Noroeste do Paraná aceitei o desafio de atuar como tutora. No ano de 1999 participei do Curso de Aperfeiçoamento para Capacitação de Tutores ofertado pela UFPR. Neste processo, foi importante estar consciente de que a prática pedagógica só se aperfeiçoa por quem a realiza, a partir de sua história de vida, dos saberes de referência, das experiências, das aspirações, das relações construídas na prática pedagógica real. E é na prática e na reflexão sobre ela que o educador consolida ou revê ações, encontra novas bases epistemológicas e descobre novos caminhos. Neste sentido, a educação a distância se constitui um campo de experiência intensamente dinâmico e inovador por trabalhar a partir da quebra de vários paradigmas educacionais que 
encontramos na educação presencial e que são, muitas vezes, assumidos com a fixidez das estruturas viciadas, e das concepções educacionais assimiladas por uma prática irrefletida. A educação a distância propõe desafios interessantes à prática pedagógica, tal como a conhecemos na educação presencial, e se apresenta um celeiro de experiências transformadoras para o educador que vivencia este processo em sua dimensão prática.

A proposta do Curso de Aperfeiçoamento para Capacitação de Tutores centrava-se em aulas teóricas, trabalhos individuais e grupais, leituras e discussões que oportunizaram momentos de reflexão sobre a nova modalidade de educação e sobre a história da EAD no Brasil mostrando um cenário de vozes variadas e divergentes sobre educação a distância.

Como profissional da educação e partícipe dos novos rumos em educação, percebi que este ambiente ofereceu um grande estímulo para que eu revisse o papel da educação, da construção do conhecimento, da interação professor-especialista, professor-tutor e a interlocução do professor-tutor e alunos. Inúmeras interrogações pairavam no imaginário pedagógico, tais como: - A EAD é um mito ou um desafio? - Qual a dimensão do projeto? - Qual a minha parcela de contribuição para que outros acreditem no projeto?

Nesse ínterim, a União Sul Brasileira de Educação e Assistência Social organizou dois Centros Associados: Maringá (PR) e Taquara (RS) de acordo com os parâmetros exigidos pela UFPR. Após os trâmites legais do convênio firmado entre a UFPR e a nossa instituição, foi divulgada a data do processo seletivo para a 1. ${ }^{a}$ turma do Curso de Pedagogia - Séries Iniciais do Ensino Fundamental na Modalidade de Educação a Distância ofertando 100 vagas para cada Centro Associado.

Iniciamos o projeto em julho de 2000, com comprometimento e também angústia, que nós educadores estávamos acreditando outra vez em sonhos e traçando projetos. Neste processo, de fazer e refazer permanente, iniciamos com os alunos uma fantástica viagem pelo mundo do aprendizado, construindo de sonho em sonho uma nova realidade: um curso de graduação de qualidade na modalidade a distância.

A aula inaugural, no Centro Associado de Maringá, ministrada pelo Coordenador do curso, Prof. Ricardo Antunes de Sá, apresentou uma breve retrospectiva da EAD e o Projeto Político Pedagógico do curso. O primeiro momento presencial aconteceu num clima de tranqüilidade entre professorespecialista, professor-tutor e alunos, no qual estes passaram a ter um espaço privilegiado para interagir, questionar e discutir.

E assim as cortinas se abriram: com mistérios, sonhos, utopias, dúvidas, muitas vozes, muitos olhares e muita expectativa pela complexidade do tra- 
balho. Portanto, chegara o momento de explorar o mundo desconhecido, descobrir novos conhecimentos, questionar, ouvir pessoas, coletar opiniões, trocar e registrar as experiências de sala de aula com outros educadores.

Eufórica com o desafio e acreditando no projeto, assumi a tutoria nas disciplinas de Concepção e Metodologia de Estudos I e II, Filosofia da Educação e Psicologia da Educação no 1. ${ }^{\circ}$ módulo. Participei com os alunos das aulas presenciais compartilhando as ansiedades, os medos e os primeiros sinais de sucesso. Encerrado o momento presencial os alunos-professores deslocaram-se para suas cidades, suas salas de aula, carregando na bagagem os livros, as apostilas, as orientações para o trabalho a distância e algumas interrogações.

Como tutora, estava consciente do papel da tutoria e do perfil dos alunos com os quais estaria interagindo a partir daquele momento. Era um grupo heterogêneo em idade, interesses, motivações e concepções sobre o curso. Alunos adultos que na maioria dos casos apresentavam insegurança e resistência a novos valores e conhecimentos, e a percepção de que a aprendizagem a distância poderia vir a ser mais ser mais lenta e mais desafiante do que parecia no naquele momento de curso, tendo em vista que vários fatores poderiam interferir no processo educativo. Na qualidade de alunos trabalhadores e pais de família, condições tais como a exigüidade de tempo para o estudo, afazeres domésticos, familiares e comunitários de seu dia-a-dia, a inicial falta de engajamento dos familiares na forma de um suporte consciente e solidário para o estudo podem ser elencados como alguns dos fatores externos desafiantes. A falta de uma disciplina e de um hábito mais consolidado de estudos, de estratégias para o planejamento de um estudo prolongado, distribuído ao longo de quatro longos anos do curso e do desconhecimento de suas reais condições de responder à esses desafios podem ser, de forma geral, contados entre outras inúmeras dificuldades relativas ao universo subjetivo dos nossos alunos.

Estas dificuldades não passaram despercebidas pelos professores que planejaram o currículo deste curso de graduação a distância, uma vez que a disciplina que abriu o curso foi dividida em dois módulos: Concepção e Metodologia de Estudos I e II. O primeiro, ministrado pelo Prof. Ricardo Antunes de Sá voltava-se para colocar o aluno o par das características da modalidade de educação a distância, seu funcionamento e seus desafios. O segundo, ministrado pela prof. ${ }^{a}$ Cristina Azra Barrenechea, destinava-se a trabalhar as atitudes, hábitos e competências necessárias para o bom proveito no estudo. Estudo esse que se faria um companheiro constante do aluno, refletindo e revelando sua imagem, suas virtudes, fraquezas, sua identidade de 
aluno a distância. Acreditamos que estes dois módulos ajudaram a inserir o aluno em uma perspectiva de autonomia e compromisso em relação ao processo de ensino e aprendizagem que se iniciava. Estes módulos também deveriam ser propostos como um curso de extensão para a capacitação dos nossos tutores por oferecerem valiosos subsídios para o estudo a distância.

Para o sucesso do trabalho de tutoria, fez-se necessário estabelecer um cronograma de atividades (bimestral-semestral). No primeiro encontro de tutoria, após o período presencial, comentamos o papel da tutoria no processo educativo. Enfoquei o papel do tutor como mediador entre professor-especialista e os alunos, um profissional comprometido com o processo ensinoaprendizagem, orientando, discutindo e analisando as produções com o objetivo de acompanhar os avanços dos alunos em suas diversas dimensões. Analisamos, também, o cronograma de atendimento, com horários definidos, destacando a importância da comunicação virtual para articulação do diálogo.

De acordo com DION (1985 apud PRETI, 1996, p. 43),

O tutor, tendo um conhecimento de base do conteúdo, é um facilitador que ajuda o estudante a compreender os objetivos do curso, um observador que reflete e um conselheiro sobre os métodos de trabalho, um psicólogo que é capaz de compreender as questões e as dificuldades do aprendiz e de ajudá-lo a responder de maneira adequada e, finalmente, um especialista em avaliação formativa.

Para reafirmar as palavras de DION (1985, apud PRETI, 1996), de que o tutor deve ser capaz de compreender as questões e as dificuldades do aprendiz, cito o exemplo de uma aluna que após o primeiro encontro presencial estava encontrando dificuldades na interpretação das leituras e produção de textos. Diante destas dificuldades ela solicitou ao marido que entrasse em contato comigo, por telefone, porque estava emocionalmente abalada, sem condições de dialogar. Ela chorava desesperadamente como uma criança quando encontra as primeiras barreiras no processo de alfabetização, sentindo-se incapaz para enfrentar o desafio. Nesse momento refleti que o meu papel não se resume apenas no auxílio para a formação acadêmica, mas também na compreensão das capacidades e limitações do ser humano.

Segundo PRETI (1996, p. 45), 
O tutor constitui um elemento dinâmico e essencial no processo ensinoaprendizagem, oferecendo aos estudantes os suportes cognitivo, metacognitivo, motivacional, afetivo e social para que estes apresentem um desempenho satisfatório ao longo do curso. Deverá, pois, ter participação ativa em todo o processo. Por isso, é importante que se estabeleça uma vinculação dialogal e um trabalho de parceria entre o tutor, o professor/especialista e a equipe pedagógica.

Pela experiência vivenciada na tutoria ressalto a importância da interlocução entre professor tutor e aluno. $\mathrm{O}$ sucesso dos sujeitos envolvidos no processo educativo depende da interação constante por meio dos meios de comunicação, respeitando a individualidade dos alunos, incentivando o intercâmbio entre os colegas e orientando o estudo independente do aluno. $\mathrm{O}$ tutor na maioria das vezes trabalha como uma caixa de ressonância para o aluno que, sem o freqüente contato da sala de aula presencial, necessita de algum referencial para balizar seu processo de aprendizagem no sentido dos objetivos didáticos traçados em cada disciplina. O envio de mensagens que demonstrem comprometimento pelo trabalho é particularmente importante para a auto-estima dos alunos.

No diálogo com os sujeitos sobre a interlocução do professor-tutor registro os seguintes depoimentos:

Ao longo de nossa existência enfrentamos toda espécie de desafios. Tais desafios é que tornam nossa vida mais interessante. Nossa formação também não deixa de ser um desses desafios, pois uma boa formação pode até não nos garantir engajar imediatamente no mercado de trabalho, porém, certamente nos fornece subsídios e melhores e maiores condições de alcançarmos nossos objetivos. Bem, no sistema presencial de formação acadêmica, enfrentamos situações complicadas, mas na modalidade à distância as complicações são quadriplicadas. Tem-se a grande necessidade de um canal seguro que viabilize a nossa comunicação com o professor, que é insubstituível. Além de viabilizar essa ponte, a tutoria ameniza a solidão e a insegurança causadas pela distância. Dessa forma uma eficaz interlocução professor-tutor-aluno é imprescindível. Em minha jornada, enquanto aluna da EAD, posso afirmar que nas situações em que necessitei da intermediação da tutora, bem como do seu apoio, obtive respostas favoráveis em pelo menos $98 \%$ das ocasiões. Os demais $2 \%$ não foram satisfatórios, não devido a falhas da tutoria, mas em razão a falhas nos meios de comunicação que dispomos, afinal as máquinas também não são perfeitas. (Rosa Maria de Oliveira) 
A interlocução entre o professor-tutor e o aluno na EAD é algo muito importante. $\mathrm{O}$ fato de não haver um número de aulas presenciais como em um curso $100 \%$ presencial, há uma necessidade dessa relação entre o professor-tutor e o aluno para a solução de dúvidas que surgem no decorrer da elaboração dos trabalhos e da leitura dos textos. Não há só a necessidade de comunicação via e-mail ou postal, mas também os encontros de tutoria são muito importantes. Essa relação é indispensável para que haja um melhor aproveitamento do curso. Então, penso que o professor-tutor deve sempre estar informado e com as leituras de texto de sua área em dia para que possa ajudar melhor àqueles que dependem dele para solucionar dúvidas. (Daniela Lamarque)

\section{Considerações finais}

Pensar novas formas de educação deve ser nossa postura como educadores, pois nos foi atribuída a missão de olhar mais longe e contribuir significativamente na preparação de transformadores sociais.

Portanto, navegar no mundo da EAD é uma aventura cercada de mistérios, desafios, sonhos e descobertas de novos sons, novas imagens, novos atores sociais. Participar desta viagem é apaixonante, pois se entra fundo em mundos desconhecidos, resgatam-se histórias de vida e participa-se coletivamente do "jogo do saber". Segundo PRETI (1996, p. 27 ), "é uma prática educativa situada e mediatizada, uma modalidade de se fazer educação, de se democratizar o conhecimento".

Em cada aventura pedagógica descobrem-se os encontros e desencontros do ensinar/aprender, e é por meio dos desafios que aprendemos uns com os outros, em um trabalho coletivo no qual sentimos segurança para errar e aprender com os próprios erros.

Para que a Educação a Distância concretize seus objetivos é fundamental que se compreenda que o Centro Associado não é um locus de transmissão de conhecimentos, mas um lugar onde se convive em sociedade e se aprende a viver em democracia, um lugar para formar a pessoa humana, sua identidade e sua cidadania e que os componentes do sistema estejam conectados entre si, isto é, exista uma real interação entre os sujeitos.

A interlocução entre o professor especialista, responsável pela preparação do material didático (impressos e multimeios) e o professor-tutor é de 
grande importância. O tutor será o mediador entre o aluno e o professor especialista, mas o sucesso do aprendizado dos alunos depende também de um equilíbrio entre, de um lado o comprometimento do tutor assumindo com responsabilidade a tarefa de orientar e acompanhar os trabalhos individuais e grupais nos momentos a distância e presencial e, de outro, o respeito pela autonomia da aprendizagem de cada aluno.

Acredito que, no momento em que os órgãos competentes assumirem o seu papel por meio de políticas públicas de financiamento e incentivo à Educação a Distância, as instituições superiores terão suporte para difundir ainda mais o trabalho que está sendo realizado hoje com grande esforço e coragem por parte de um grupo de pioneiros que estão imprimindo, na história desta modalidade, uma marca de idealismo e compromisso com a qualidade. Com o apoio governamental, a educação a distância conquistará seu espaço em nosso país. Desta forma, grande parte da população que se encontra marginalizada e excluída socialmente por não ter acesso à escola, poderá ter a oportunidade de qualificar-se e poderá ver transformando-se em realidade um sonho que é de muitos.

\section{REFERÊNCIAS}

DIDONET, V. Por uma escola do nosso tempo. Revista Pátio, n. 5, p. 44-47, maio/jun. 1998.

MARTINS, O. B. A educação superior a distância e a democratização do saber. Petrópolis: Vozes, 1991.

PRETI, O. (Org.). Educação a distância: inícios e indícios de um percurso. Cuiabá: UFMT - Nead/IE, 1996. . Educação a distância: construindo significados. Brasília: Plano, 2000.

Texto recebido em 20 jan. 2003 Texto aprovado em 20 de mar. 2003 